\title{
Measurement of Glycosylated Haemoglobin at High Altitudes
}

Dear Sir,

We would like to report a modification of the colorimetric method for measurement of glycosylated haemoglobin. This method has been described in detail by Fischer et al. [1] and shown to give reproducible results which correlate well with glycaemic control when the oxalic acid incubation is continued for $4.5 \mathrm{~h}$.

At the high altitude of Mexico City a water bath boils at $93.5^{\circ} \mathrm{C}$ and therefore the oxalic acid reaction is not completed even after 6 or $7 \mathrm{~h}$ in the water bath. Because of this problem, we have investigated the use of a pressure cooker to heat samples for $2 \mathrm{~h}$ at $250^{\circ} \mathrm{C}$ and $15 \mathrm{lbs} / \mathrm{square}$ inch $\left(1.1 \mathrm{~kg} / \mathrm{cm}^{2}\right)$. Under these conditions the reaction is completed in $2 \mathrm{~h}$, enabling samples to be processed much more quickly.

The correlation coefficient between repeated fasting blood glucose concentrations and glycosylated haemoglobin in stable diabetic patients is 0.91 and the normal range for the method is $6 \%-8 \%$.

Yours sincerely,

R.Paisey, V.Valles, G. Arredondo, B. Wong and O.Lozano-Castañeda

\section{Reference}

1. Fischer RW, De Jong C, Voigt E, Berger W, Winterhaltec KH (1980) The colorimetric determination of $\mathrm{HbA}_{1 \mathrm{c}}$ in normal and diabetic subjects. Clin Lab Haematol 2: 129-138

Dr. R. Paisey

Departamento de Diabetes y Metabolismo de Lipidos

Instituto Nacional de la Nutricion

Av. San Fernando y Viaducto Tlalpan

14000 Mexico, DF, Mexico

\section{HDL Cholesterol and Fasting Insulin Levels}

Dear Sir,

I was interested in the observation of Stalder et al. [1] that in normal males there was a negative correlation between fasting insulin levels and concentrations of HDL cholesterol. This adds a further strand to the complex web of factors involved in atherogenesis. However, I was surprised at the low degree of correlation between fasting plasma insulin levels and the weight index used. This was to me - an unfamiliar index and I would be interested to know how well it correlates with more exact estimates of body fat. The body mass index (weight/height ${ }^{2}$ ), for instance, which is commonly used, has a coefficient of correlation with adipose tissue mass of about 0.75 [2]. I wonder whether use of the latter index would give a better correlation with insulin values, also whether an appropriate analysis of variance would reveal a statistically independent relationship between plasma insulin and HDL cholesterol when plasma triglycerides and body mass index were included in the analysis.

In a study which antedated the current interest in HDL cholesterol $[3,4]$, we found that in men, but not in women, fasting plasma insulin levels were negatively correlated with total calorie intake. Although body mass index was the strongest correlate of plasma insulin, the insulin/diet relationship was statistically independent of this [4].

Thus, in epidemiological studies looking at the relationship of coronary heart disease and plasma insulin, we may also be looking at possibly confounding relationships with diet and HDL cholesterol, at least in the male sex. We clearly require more knowledge of intermediary metabolism to make biological sense of these statistical correlations.

Yours sincerely, R. J. Jarrettt

\section{References}

1. Stalder M, Pometta D, Suenram A (1981) Relationship between plasma insulin levels and high density lipoprotein cholesterol levels in healthy men. Diabetologia $21: 544-548$

2. Weinsier RL, Fuchs RJ, Kay TD, Triebwasser JH, Lancaster MC (1976) Body fat: its relationship to coronary heart disease, blood pressure, lipids and other factors measured in a large male population. Am J Med 61: 815-824

3. Boyns DR, Crossley JN, Abrams ME, Jarrett RJ, Keen H (1969) Oral glucose tolerance and related factors in a normal population sample (1) Blood sugar, plasma insulin, glyceride and cholesterol measurements and the effects of age and sex. Brit med $\mathrm{J}$ 1:595-598

4. Thomas BJ, Jarrett RJ, Keen H, Ruskin HJ (1982) Relation of habitual diet to fasting plasma insulin concentration and the insulin response to oral glucose. Clin Nutr (in press)

Dr. R. J.Jarrett

Department of Community Medicine

Guy's Hospital Medical School

London SE1 9RT, UK 